\title{
Relationship between quality of life, depression and anxiety in type 1 and type 2 diabetes
}

\author{
Soner Cakmak ${ }^{1 \oplus}$, Emirhan Gen ${ }^{2}$ \\ ${ }^{1}$ Cukurova University, Faculty of Medicine, Department of Psychiatry, Adana - Turkey \\ ${ }^{2}$ Cag University, Social Sciences Institute Psychology, Mersin - Turkey
}

\begin{abstract}
Objective: Physical, cognitive and emotional changes in diabetic patients affect the treatment process and quality of life. The aim of this study was to investigate the relationship between depression and anxiety symptoms and quality of life in diabetic patients and the differences of these variables with regard to some sociodemographic factors and the type of diabetes.

Method: The study sample consisted of 202 patients with diabetes mellitus (83 type 1, 119 type 2 diabetes) admitted to a wellness center in Adana. The World Health Organization Quality of Life Questionnaire, Beck Depression Inventory and Beck Anxiety Inventory were administered to the participants. Their sociodemographic information, body mass index, and smoking and alcohol use status were recorded.

Results: The quality of life subscales were lower (general health $p=0.009$, physical health $p=0.005$, psychological health $p=0.022$, social relations $p<0.001$, environment $p=0.005)$ and depression and anxiety symptom levels were higher $(p=0.03$, $p=0.02$ ) in patients with type 1 diabetes than in type 2 . Depression and anxiety severity were found to be independent factors affecting all quality of life levels $(p<0.01)$ and diabetes type was an independent factor for social quality of life $(p=0.027)$. The general quality of life subscale score for women $(p=0.042)$ and general, physical and psychological quality of life subscales scores of the obese $(p=0.042, p=0.016, p=0.045)$ were low. With higher education level and lower age, quality of life was found to increase $(p<0.05)$ while depression and anxiety levels decreased $(p<0.01)$. There was a negative correlation between smoking $(p=0.035)$ and quality of life and a positive correlation with anxiety level $(p=0.018)$.

Conclusion: Diabetes type, depression and anxiety are predictors of quality of life in diabetic patients. Age, weight, low education level, and smoking were also associated with poor quality of life and depression and anxiety symptom severity in diabetic patients.
\end{abstract}

Keywords: Anxiety, depression, diabetes, quality of life

\section{INTRODUCTION}

A booklet on the diagnosis and treatment of diabetes published in 2017 by the Turkish Diabetes Foundation defined diabetes mellitus (DM) as a "chronic metabolic disease characterized by hyperglycemia caused by a defect in insulin secretion or insulin action or both factors" (1). In addition to being a metabolic disease, $\mathrm{DM}$ is a chronic condition causing psychological and social problems for the affected persons. The first, and most comprehensive, classification for this disease, which previously had been divided into two types, insulin-dependent and non-insulin-dependent DM, was published in 1980 by the World Health

How to cite this article: Cakmak S, Gen E. Relationship between quality of life, depression and anxiety in type 1 and type 2 diabetes. Dusunen Adam The Journal of Psychiatry and Neurological Sciences 2020;33:155-169.

Correspondence: Soner Cakmak, Cukurova University, Faculty of Medicine, Department of Psychiatry, Sarıcam, Adana - Turkey 
Organization (WHO). It was updated in 1985 and 1998 and has also been adopted by the American Diabetes Association. This classification distinguishes 4 groups according to clinical characteristics: type 1, type 2, gestational, and specific types of diabetes.

Due to some chronic complications, diabetes can cause emotional, cognitive, and physical problems such as worries about body image, stress, future life anxiety, worry of inadequacy, or fear of becoming dependent on others (2). These issues may interfere with diabetic patients' socializing and even endanger their lives. Accordingly, a number of studies have investigated the impact of physical, cognitive, and emotional changes on the treatment of diabetes and patient's quality of life. Quality of life is accepted as a significant indicator for the course of the disease in DM (3-6). Good glycemic control (7), a reduction of severe metabolic complications (8), regular exercise (9), and improvement in compliance with behavioral models like education about the disease, healthy nutrition, and stress management (10) have been shown to increase the quality of life for persons with diabetes. On the other hand, acute complications like hypo- and hyperglycemia and chronic complications such as cardiovascular diseases, chronic renal failure, problems with vision, peripheral neuropathy, and impotence, obesity, and intense medical treatment have been reported as factors reducing the quality of life $(8,9,11-13)$.

Numerous studies also demonstrated a relevant relation between diabetes and psychiatric disorders. Eren and Erdi (14) reported major depressive disorder in $68 \%$ of diabetic patients with complications, in $10 \%$ generalized anxiety, and in 10\% obsessive-compulsive disorder. Studies on the prevalence of depression in diabetics reached a variety of different results, but in general, the prevalence of depressive symptoms was between $18 \%$ and $30 \%(15,16)$. Studies on the relations between depression and diabetes discuss 3 relevant mechanisms: First, high cortisol levels in the hypothalamus-pituitary axis and reduced insulin sensitivity cause irregularities in blood glucose levels; second, increased emotional distress due to diabetes may lead to depression; third, hypo- and hyperglycemia can cause negative emotional stress (17).

In the combination of depression and diabetes, the chronic activation of the stress system is thought to be a common path. Chronic stress activates the hypothalamus-pituitary-adrenal (HPA) axis and the sympathetic nervous system (SNS), increasing the production of cortisol in the adrenal cortex and adrenalin and noradrenalin in the medulla of the adrenal gland (18). Chronic hypercortisolemia and long-term SNS activation may trigger insulin resistance and visceral obesity, leading to metabolic syndrome and type 2 diabetes (19). On the other hand, excessive cortisol affects neurogenesis in the hippocampus, which plays a role in depression and type 2 diabetes $(20,21)$. Chronic stress also increases the production of inflammatory cytokines. Cytokines have been reported to cause immune function disorder (either directly or via the HPA axis or the SNS) and thus induce insulin resistance in pancreas $\beta$-cells and increase the risk of type 2 diabetes $(22,23)$. Several recent studies have also shown inflammatory responses to play a role in the pathophysiology of depression. Proinflammatory cytokines have been found to affect a number of pathophysiological areas related with depression such as neurotransmitter metabolism, neuroendocrine function, and synaptic plasticity (24). These correlations support the idea that stress (via the HPA axis and due to chronic SNS activation) and inflammation may cause both depression and type 2 diabetes, suggesting a link connecting these conditions. The close chronological relation between type 1 diabetes and the onset of depression is also conspicuous: The burden of type 1 diabetes diagnosis and treatment occurs in a period of increased predisposition for depression (25). There are not many studies examining the pathophysiological relation between type 1 diabetes and depression. However, it has been reported that an increased cytokine level in the circulation, which disturbs neurogenesis and neurotransmitter metabolism, may cause a deficit of insulin, while chronic and iatrogenic hyperglycemia may lead to hyperactivity in the HPA axis; type 1 diabetes increases the burden of depression, and type 1 diabetes shares pathophysiological pathways with depression (26).

Depression is known to complicate the control of diabetes-related symptoms (27), affect diet therapy, exercise, and blood glucose control (28), and increase bad nutritional habits and non-compliance with drug use; it has been reported that depressive diabetics are 3 times more likely to fail to observe their diet than nondepressive patients (29). In addition, it has been reported that a stressful lifestyle of individuals with a high level of depressive behaviors before becoming diabetic may cause an inability to achieve hormonal control, and the increased level of free oxygen radicals in the body may pose a physiological death risk for pancreas $\beta$-cells or accelerate pathological death $(30,31)$.

A number of studies also reported increased anxiety levels in diabetics (16\%-40\%) compared to normal 
controls $(2,15,32,33)$. Studies on the comorbidity of diabetes and anxiety showed that diabetes-related complications, a rising number of hospitalizations due to diabetes, lack of information about diabetes, unemployment, low levels of education and income, and the use of insulin may increase the anxiety level $(2,15,33)$. A heightened anxiety level in DM patients not only affects the course of the disease negatively, it also reduces compliance with treatment and reduces the quality of life. Zhang et al. (34) found that around $25 \%$ of patients with type 2 diabetes showed clinical signs of anxiety. A study on anxiety and depression levels in diabetic children found anxiety disorder to be the second-most common psychiatric condition in type 1 diabetes after depression (35).

The main aims of diabetes therapy are metabolic control, prevention or delay of the development of complications, and increasing the quality of life and to enable a physically, psychologically, and mentally regular way of life. Studies have shown that diabetes, depression, and anxiety symptoms share certain pathophysiological mechanisms; symptoms related to these 2 psychological states may appear during the course of diabetes and affect the patients' quality of life indirectly in the treatment process and in their social adaptation.

Aim of our research was to establish the relation between the severity of depression and anxiety symptoms and quality of life in diabetic patients and to investigate differences related to some sociodemographic variables and by diabetes type. Our hypothesis was that sex, age, marital status and education level, smoking and alcohol consumption, the Body Mass Index (BMI), and the type of diabetes may make a difference for quality of life and severity of depression and anxiety symptoms. We suggest that clarifying the relation between quality of life, anxiety, and depression in diabetic patients and the factors involved can provide guidance for area experts working with diabetics, helping them increase their patients' quality of life and preventing the development of depression and anxiety.

\section{METHOD}

This study has been designed according to the relational screening model. The study sample consists of diabetic patients attending a wellness center in Adana. In this center, chronically ill patients (diabetics, hypertension, obesity, diseases of the musculoskeletal system) and normal healthy individuals are following dietary and exercise programs under the guidance of a dietician, a sports trainer, and a physiotherapist. During the period when the measurement instruments were administered, in accord with the research aim only diabetic patients were selected from among the persons attending the wellness center. Participants who had been diagnosed with diabetes at least 2 years earlier, completed primary school or above, and were between 18 and 70 years of age were enrolled in the study; time of diagnosis and type of diabetes were established from the participants' statements and from their medical records. Patients with psychiatric comorbidities or currently being in psychiatric treatment were excluded from the study. In the 2 -month research period, of the 480 persons registered at the wellness center, 259 had a diagnosis of diabetes, and the measurement instruments were administered to 224 diabetic patients who had given their consent. After excluding 22 participants who had completed the forms inadequately or incompletely, the final sample consisted of 202 diabetics, of whom 83 were diagnosed with type 1 and 119 with type 2 diabetes. The sampling method used in this study was purposeful random sampling. Written and oral consent declaring their willingness to participate in the research was received from the participants. The forms were administered in May and June, 2019 and digitized in July, 2019. This study has been carried out in conformity with the internationally recognized Helsinki Declaration of 1964, latest revision 2013, and approval from the scientific research ethics committee of Cag University was given on March 25, 2019, document no: 999.

\section{Measures}

Personal Data Form: The personal data form recorded information about participants' sex, age, marital status, education level, smoking and alcohol consumption, BMI, type of diabetes, and type of antidiabetic treatment (exercise/physical activity, diet/medical nutrition, oral antidiabetic, insulin). A BMI $<25 \mathrm{~kg} / \mathrm{m}^{2}$ was considered normal, a BMI of $25-30 \mathrm{~kg} / \mathrm{m}^{2}$ as overweight, and a BMI $>30 \mathrm{~kg} / \mathrm{m}^{2}$ as obese.

World Health Organization Quality of Life Questionnaire (WHOQOL-27): This health-related quality-of-life scale was developed by the WHO (36). Eser et al. (37) studied the validity and reliability of the Turkish adaptation. There are two versions of the original form, a long (WHOQOL-100) and a short form (WHOQOL-BREF). The instrument measures physical, psychological, social, and environmental aspects of wellbeing; the short form includes 26 items. In the Turkish version, where a 27 th item has been added (WHOQOL-27), the environment domain score is 
referred to as Environmental-TR. In each domain, the quality of life in the specific field is expressed independently from the others. Higher scores indicate increased quality of life. Items on the questionnaire are scored between 1 and 5 on a Likert-type scale. Items 3, 4 , and 26 are reverse-scored. The subdimension general health is evaluated with items 1 and 2, physical health with items $3,4,10,15,16,17$, and 18 , psychological health with items $5,6,7,11,19$, and 26 , social relationships with items 20,21 , and 22 , and the subdimension environment with items $8,9,12,13,14$, $23,24,25$, and 27 . The total points for each subdimension constitute the raw score for that subdimension. The number resulting from subtracting the minimal score of the subdimension from the raw score is divided by the difference between the highest and the lowest score for the subdimension and multiplied by 100 to determine the percentage score for the respective subdimension.

Beck Depression Inventory (BDI): This instrument measures the physical, emotional, cognitive, and motivational symptoms seen in depression. The purpose of this scale is not to diagnose depression, but to assess the depression risk and to measure changes in the level and severity of depressive symptoms. Developed in 1961 by Beck et al. (38), the validity and reliability of the Turkish version was studied by Hisli (39). The inventory contains 21 self-assessment statements scored on a 4-point Likert-type scale. Each item can be given between 0 and 3 points, resulting in a total score between 0 and 63 . A high total score indicates a high level or intensity of depression. The validity and reliability study for the Turkish version established a cutoff point of 17 , interpreting a score of $0-10$ points as no depression, 11-17 mild, 18-23 points as moderate, and 24 and above as severe level of depression.

Beck Anxiety Inventory (BAI): This self-report scale is used to determine the severity of anxiety symptoms a person experiences. It is scored on a Likerttype scale. For each of the 21 statement categories, 4 answers are offered. Each item is scored between 0 and 3 . The level of the points on the scale indicates the severity of the anxiety a person experiences. A validity and reliability study for Turkey has been carried out by Ulusoy et al. (40). BAI scores of 0-17 are interpreted as a low level of anxiety, 18-24 as moderate, 25 and above as a high level of anxiety (41).

\section{Statistical Analyses}

Data were tested for normal distribution using normal distribution tests and histograms. In the analysis of normally distributed continuous variables, t-test, oneway analysis of variance (ANOVA), and Pearson correlation tests were used. Not normally distributed continuous variables were analyzed using MannWhitney U test, Kruskall-Wallis test, and Spearman correlation tests. A correlation coefficient ( $r)<0.2$ was interpreted as showing a very weak or no fit/correlation; a value between 0.2 and 0.4 was accepted as a weak correlation, between 0.4 and 0.6 as moderate, between 0.6 and 0.8 as good correlation, and $r>0.8$ was considered an excellent fit/correlation. Results are presented as mean \pm standard deviation, median (minimum-maximum), and $\mathrm{n}$ and percentage. A value for $\mathrm{p}<0.05$ was considered as statistically significant. To obtain the independent variables determining quality of life (such as sex, age, marital status, education level, BMI, diabetes type, anxiety and depression levels), multiple regression analysis was performed. Statistical analyses were done using SPSS version 22.0 (Armonk, NY: IBM Corp.)

\section{RESULTS}

Of the diabetic patients participating in the study $(n=202), 41.1 \%$ had type 1 diabetes $(n=83)$ and $58.9 \%$ type 2 diabetes $(n=119)$. Participants' mean age was $43.46 \pm 13.38$ (for type 1 diabetics $43.37 \pm 12.87$, for type 2 diabetics $43.52 \pm 13.79)$. All patients with type 1 diabetes were using insulin: insulin only $84.3 \%$, insulin + oral antidiabetic drug $15.7 \%$. Of the type 2 diabetics, $51.3 \%$ only used exercise and diet as therapy and $43.7 \%$ only oral antidiabetic therapy, while $5.0 \%$ used oral antidiabetics alongside insulin therapy. No statistically significant difference was found between the types of diabetes for the variables sex, age, marital status, education level, and smoking. Only BMI and alcohol consumption differed statistically significantly between the groups. The ratio of obese patients was higher among type 2 diabetics (20.2\%) than among type 1 diabetics $(7.2 \%)(\mathrm{p}<0.039)$. The ratio of alcohol consumption was higher among type 1 diabetics $(39.8 \%)$ than among type 2 diabetics $(21 \%)(\mathrm{p}<0.002)$ (Table 1).

Descriptive statistics for the WHOQOL-27, BDI, and BAI scores by diabetes type are presented in Table 2. All subdimensions of quality of life showed significant differences according to diabetes type (general health [t=2.628; $\mathrm{p}=0.009]$, physical health [ $\mathrm{t}=2.864 ; \mathrm{p}=0.005]$, psychological health $[\mathrm{t}=2.315 ; \mathrm{p}=0.022]$, social relations $[t=3.909 ; \mathrm{p}<0.001]$, environment $[\mathrm{t}=2.853 ; \mathrm{p}=0.005])$. In type 2 diabetics, general, physical, psychological, 
Table 1: Distribution of participants' sociodemographic and physical characteristics, smoking status, and alcohol consumption by diabetes type

Diabetes type

\begin{tabular}{|c|c|c|c|c|}
\hline Type 1 (n=83) & \multicolumn{2}{|c|}{ Type 2 (n=119) } & \multicolumn{2}{|c|}{ Total $(n=202)$} \\
\hline$\%$ & $\mathbf{n}$ & $\%$ & $\mathbf{n}$ & $\%$ \\
\hline
\end{tabular}

Sex

$\begin{array}{lllllll}\text { Female } & 36 & 43.4 & 66 & 55.5 & 102 & 50.5 \\ \text { Male } & 47 & 56.6 & 53 & 44.5 & 100 & 49.5\end{array}$

Age

20-44

44-64

$65+$

49
28
6

59.0

33.7

7.2

30.1

Married

25

Single

37

44.6

Divorced

Widowed

13

8

15.7

9.6

\section{Education level}

Primary school or below

Middle school

High school

Undergraduate

Graduate

BMI

Normal

Overweight

Obese

\section{Smoking}

Smoker

Quit

Never smoked

\section{Alcohol consumption}

Drinking

Quit

Never drank

Chi-square test, n: number of participants, ${ }^{*} p<0.05$, BMl: Body Mass Index

social, and environmental quality of life scores were found to be statistically higher than in type 1 diabetics.

The mean BDI score for all 202 participants was $16.2 \pm 12.9$, the mean BAI score $20.7 \pm 11.4$. Depression and anxiety symptom severity in type 1 diabetic patients was significantly higher than in type 2 diabetics ( $\mathrm{t}=-$ 2.965; $\mathrm{p}=0.003),(\mathrm{t}=-3.184 ; \mathrm{p}=0.002)$ (Table 2).

In Table 3, the relation between subscales of quality of life and depression and anxiety symptom severity is presented through correlation analysis. A significant negative correlation has been found between all subscales and anxiety and depression symptom severity: With increasing anxiety and depression symptom severity, quality of life declines.

Negative correlations at a good level have been found between general health and BDI/BAI $(r=-0.71$; $r=-0.64$, resp.), physical health and BDI/BAI ( $r=-0.77$; $\mathrm{r}=-0.74$, resp.), and psychological health and BDI/BAI $(r=-0.61 ; r=-0.65$, resp.). For the variables social relations and environment, negative correlations at a 
Table 2: Distribution of participants' WHOQOL-27, BDI, and BAI scores by diabetes type

\begin{tabular}{|c|c|c|c|c|c|c|c|c|c|c|c|c|c|}
\hline & \multicolumn{13}{|c|}{ Diabetes type } \\
\hline & \multicolumn{3}{|c|}{ Type $1(n=83)$} & \multicolumn{3}{|c|}{ Type 2 (n=119) } & \multicolumn{3}{|c|}{ Total $(n=202)$} & \multirow[t]{2}{*}{$\mathbf{t}$} & \multirow[t]{2}{*}{ df } & \multirow[t]{2}{*}{ d } & \multirow[t]{2}{*}{$\mathbf{p}$} \\
\hline & Mean & SD & Med. & Mean & SD & Med. & Mean & SD & Med. & & & & \\
\hline \multicolumn{14}{|l|}{ WHOQOL-27 } \\
\hline General Health & 38.7 & 21.9 & 38 & 47.1 & 22.5 & 50 & 43.6 & 22.6 & 38 & 2.628 & 200 & 0.37 & 0.009 \\
\hline Physical Health & 48.9 & 18.6 & 43 & 56.4 & 18.0 & 57 & 53.3 & 18.6 & 54 & 2.864 & 200 & 0.40 & 0.005 \\
\hline Psychological & 54.7 & 18.1 & 54 & 61.0 & 19.6 & 58 & 58.4 & 19.2 & 57 & 2.315 & 200 & 0.33 & 0.022 \\
\hline Social relations & 50.0 & 19.7 & 50 & 61.1 & 19.9 & 58 & 56.5 & 20.5 & 50 & 3.909 & 200 & 0.54 & $<0.001$ \\
\hline Environment-TR & 57.4 & 16.6 & 58 & 63.9 & 15.1 & 61 & 61.2 & 16.1 & 61 & 2.853 & 200 & 0.40 & 0.005 \\
\hline BDI & 19.3 & 13.2 & 20 & 14.0 & 12.3 & 13 & 16.2 & 12.9 & 17 & -2.965 & 200 & -0.42 & 0.003 \\
\hline BAI & 23.7 & 11.9 & 22 & 18.6 & 10.6 & 17 & 20.7 & 11.4 & 20 & -3.184 & 200 & -0.45 & 0.002 \\
\hline
\end{tabular}

Independent-samples t-test, n: Number of participants, WHOQOL-27: World Health Organization Quality of Life Questionnaire, BDI: Beck Depression Inventory, BAI: Beck Anxiety Inventory, SD: Standard deviation, df: Degrees of freedom, d: Cohen's d, Med.: Median

good level have been found with BDI and BAI, as well (social relations $r=-0.76 ; r=0.60$; environment $r=-0.67$; $\mathrm{r}=-0.68$ ) (Table 3).

When examining the distribution of quality of life and depression and anxiety symptom severity according to sex, age, marital status, education level, smoking, alcohol consumption, and BMI groups, we find the highest mean value for women in the variable psychological health and the highest mean for men in the variable environment. In women, the general health score in quality of life was found to be statistically significantly lower than in men $(t=-2.043 ; p=0.042)$. For the other variables, no statistically significant differences between the sexes were found.

When assessing the quality of life subdimensions of diabetics by marital status group, we find the highest mean values for the variables general, physical, psychological, and environmental quality of life in the single group, the lowest mean in the widowed group, except for environment, where the lowest mean value was found in the divorced group. For the BDI and BAI variables, the lowest mean scores were in the single group, the highest in the widowed group (Table 4). While being single showed a positive effect on all subdimensions of quality of life in diabetic patients, a negative effect was seen on depression and anxiety symptom severity. Furthermore, compared to married diabetics, the quality of life of widowed patients declined and depression and anxiety symptom severity increased.

With increasing level of education, all quality of life subdimensions except for environment increased their scores significantly (general health $[\mathrm{F}=9.706 ; \mathrm{p}=0.0001]$, physical health $[\mathrm{F}=10.447 ; \mathrm{p}=0.0001]$, psychological health $[\mathrm{F}=3.06 ; \mathrm{p}=0.018]$, and social relations $[\mathrm{F}=3.132$; $\mathrm{p}=0.016])$. BDI and BAI scores increased with falling education level $([\mathrm{F}=3.677 ; \mathrm{p}=0.007], \quad[\mathrm{F}=4.987$; $\mathrm{p}=0.0001]$, respectively).

When analyzed by BMI, general, physical, and psychological subscale mean scores were significantly

Table 3: Correlation coefficients between quality of life subscales, BDI, and BAI

\begin{tabular}{|c|c|c|c|c|c|c|c|c|}
\hline & & General health & Physical & Psychological & Social & Environment TR & BDI & BAI \\
\hline General Health & $r$ & 1 & 0.75 & 0.59 & 0.66 & 0.55 & -0.71 & -0.64 \\
\hline Physical Health & r & & 1 & 0.70 & 0.72 & 0.69 & -0.77 & -0.74 \\
\hline Psychological & r & & & 1 & 0.53 & 0.73 & -0.61 & -0.65 \\
\hline Social relations & r & & & & 1 & 0.65 & -0.76 & -0.60 \\
\hline Environment-TR & r & & & & & 1 & -0.67 & -0.68 \\
\hline BDI & r & & & & & & 1 & 0.68 \\
\hline BAI & r & & & & & & & 1 \\
\hline Mean & & 43.63 & 53.32 & 58.44 & 56.52 & 61.22 & 16.17 & 20.67 \\
\hline SD & & 22.56 & 18.56 & 19.21 & 20.48 & 16.05 & 12.88 & 11.37 \\
\hline $\mathbf{a}$ & & 0.80 & 0.90 & 0.88 & 0.81 & 0.87 & 0.96 & 0.92 \\
\hline
\end{tabular}

Pearson correlation, all correlations are significant at the level of p<0.001, BDI: Beck Depression Inventory, BAI: Beck Anxiety Inventory, a: Cronbach's alpha 
Table 4: Distribution of quality of life subdimensions, depression, and anxiety levels according to sex, age, marital status, education level, BMI, smoking, and alcohol consumption

\begin{tabular}{|c|c|c|c|c|c|c|c|c|}
\hline & & General & Physical & Psychological & Social & Environment-TR & BDI & BAI \\
\hline \multicolumn{9}{|l|}{ Sex } \\
\hline \multirow[t]{2}{*}{ Female } & Mean & 40.4 & 51.6 & 59.0 & 56.2 & 60.6 & 16.3 & 21.8 \\
\hline & SD & 21.7 & 18.8 & 18.7 & 20.6 & 15.0 & 12.2 & 11.9 \\
\hline \multirow[t]{6}{*}{ Male } & Mean & 46.9 & 55.1 & 57.8 & 56.8 & 61.8 & 16.0 & 19.5 \\
\hline & SD & 23.1 & 18.2 & 19.8 & 20.5 & 17.2 & 13.6 & 10.7 \\
\hline & $\mathrm{t}$ & -2.043 & -1.355 & 0.447 & -0.216 & -0.536 & 0.140 & 1.488 \\
\hline & $d f$ & 200 & 200 & 200 & 200 & 200 & 200 & 200 \\
\hline & $d$ & -0.29 & -0.19 & 0.06 & -0.03 & -0.08 & 0.02 & 0.21 \\
\hline & $\mathrm{p}$ & 0.042 & 0.177 & 0.655 & 0.829 & 0.593 & 0.889 & 0.138 \\
\hline \multicolumn{9}{|c|}{ Marital status } \\
\hline \multirow[t]{2}{*}{ Single } & Mean & 52.0 & 59.7 & 64.6 & 61.0 & 66.2 & 13.2 & 16.5 \\
\hline & SD & 22.3 & 18.9 & 18.5 & 22.0 & 16.3 & 13.5 & 10.4 \\
\hline \multirow[t]{2}{*}{ Married } & Mean & $39.7^{*, \#}$ & $51.2^{*, \#}$ & $56.3^{*, \#}$ & $55.1^{*}$ & $59.8^{*}$ & $16.9^{*, \#}$ & $21.1^{* *, \#}$ \\
\hline & SD & 21.5 & 16.6 & 19.3 & 19.1 & 15.1 & 12.0 & 10.1 \\
\hline \multirow[t]{2}{*}{ Divorced } & Mean & $35.3^{* *}$ & $48.1^{* *}$ & $50.9^{* *}$ & $51.8^{* *}$ & $52.7^{* *}$ & $19.4^{* *}$ & $26.7^{* *}$ \\
\hline & SD & 18.3 & 17.4 & 18.2 & 19.8 & 13.9 & 11.7 & 11.9 \\
\hline \multirow[t]{6}{*}{ Widowed } & Mean & $29.2^{* * *}$ & $37.7^{* * *}$ & $46.8^{* * *}$ & $46.3^{* * *}$ & $53.5^{* * *}$ & $23.8^{* * *}$ & $31.2^{* * *}$ \\
\hline & SD & 18.2 & 12.7 & 13.2 & 13.2 & 12.7 & 10.8 & 9.9 \\
\hline & $\mathrm{F}$ & 9.285 & 9.716 & 7.287 & 3.533 & 7.156 & 4.469 & 13.365 \\
\hline & $d f$ & 3.198 & 3.198 & 3.198 & 3.198 & 3.198 & 3.198 & 3.198 \\
\hline & $\eta^{2}$ & 0.12 & 0.13 & 0.10 & 0.05 & 0.10 & 0.06 & 0.17 \\
\hline & $\mathrm{p}$ & 0.0001 & 0.0001 & 0.0001 & 0.016 & 0.0001 & 0.005 & 0.0001 \\
\hline
\end{tabular}

Multiple comparison between groups (Post hoc test): ${ }^{*} \mathrm{p}<0.05$ between married and singles, ${ }^{* *} \mathrm{p}<0.05$ between divorced and singles, ${ }^{* * *} \mathrm{p}<0.05$ between widowed and single, $\# \mathrm{p}<0.05$ between married and widowed

\begin{tabular}{lcccccccc}
\hline Education level & & & & & & & & \\
Primary & Mean & 28.6 & 38.4 & 50.3 & 48.5 & 55.1 & 22.2 & 27.5 \\
Middle school & $\mathrm{SD}$ & 17.6 & 12.9 & 12.6 & 15.9 & 11.6 & 11.0 & 9.3 \\
& Mean & 32.0 & 47.7 & 53.3 & 50.7 & 60.6 & 20.1 & 23.8 \\
High school & $\mathrm{SD}$ & 18.8 & 17.0 & 15.3 & 13.4 & 10.6 & 11.0 & 9.3 \\
& Mean & $46.7^{*}$ & $53.8^{*}$ & $60.4^{*}$ & $56.6^{*}$ & 60.1 & $15.0^{*}$ & $19.1^{*}$ \\
Undergraduate & $\mathrm{SD}$ & 20.7 & 19.5 & 22.8 & 23.8 & 19.3 & 13.6 & 11.4 \\
& Mean & $49.6^{* *}$ & $58.0^{* *}$ & $60.7^{* *}$ & $60.2^{* *}$ & 63.0 & $13.8^{* *}$ & $18.9^{* *}$ \\
Graduate & $\mathrm{SD}$ & 21.8 & 17.2 & 20.4 & 21.9 & 17.4 & 13.3 & 12.1 \\
& $\mathrm{Mean}$ & $55.4^{* * *}$ & $65.8^{* * *}$ & $65.5^{* * *}$ & $63.9^{* * *}$ & 67.2 & $12.2^{* * *}$ & $16.1^{* * *}$ \\
& $\mathrm{SD}$ & 24.5 & 14.7 & 14.4 & 17.7 & 13.4 & 11.4 & 10.0 \\
& $\mathrm{~F}$ & 9.706 & 10.447 & 3.063 & 3.132 & 2.085 & 3.677 & 4.987 \\
& $\mathrm{df}$ & 4.197 & 4.197 & 4.197 & 4.197 & 4.197 & 4.197 & 4.197 \\
& $\mathrm{\eta}^{2}$ & 0.17 & 0.18 & 0.06 & 0.06 & 0.04 & 0.07 & 0.09 \\
& $\mathrm{p}$ & 0.0001 & 0.0001 & 0.018 & 0.016 & 0.084 & 0.007 & 0.001 \\
\hline
\end{tabular}

Multiple comparison between groups (Post hoc test): ${ }^{*} \mathrm{p}<0.05$ between graduate and primary school, ${ }^{* *} \mathrm{p}<0.05$ between graduate and primary school, ${ }^{* * *} \mathrm{p}<0.05$ between high school and primary

lower in obese patients than in overweight and normal diabetics $([\mathrm{F}=3.219 ; \mathrm{p}=0.042],[\mathrm{F}=4.243 ; \mathrm{p}=0.016]$, $[\mathrm{F}=3.144 ; \mathrm{p}=0.045]$, respectively). No significant difference was found between overweight and normal weight participants. In other words, there is a negative correlation between quality of life and obesity, but now 
Table 4: Cont.

\begin{tabular}{|c|c|c|c|c|c|c|c|c|}
\hline & & General & Physical & Psychological & Social & Environment-TR & BDI & BAI \\
\hline \multicolumn{9}{|l|}{ BMI } \\
\hline \multirow[t]{2}{*}{ Normal } & Mean & $45.7^{*}$ & $55.6^{*}$ & $61.4^{*}$ & 56.9 & 62.3 & 15.2 & $18.6^{*}$ \\
\hline & SD & 23.1 & 17.9 & 18.5 & 20.6 & 15.7 & 12.8 & 11.0 \\
\hline \multirow[t]{2}{*}{ Overweight } & Mean & $44.6^{* *}$ & $53.6^{* *}$ & $56.7^{* *}$ & $58.0^{*}$ & 61.7 & 15.4 & $21.9 * *$ \\
\hline & SD & 21.2 & 18.3 & 19.8 & 20.7 & 16.9 & 12.4 & 11.3 \\
\hline \multirow[t]{6}{*}{ Obese } & Mean & 34.2 & 44.6 & 52.2 & 51.9 & 56.4 & 21.3 & 25.1 \\
\hline & SD & 22.0 & 19.4 & 19.0 & 19.7 & 15.0 & 13.4 & 11.6 \\
\hline & $\mathrm{F}$ & 3.219 & 4.243 & 3.144 & 0.932 & 1.643 & 2.819 & 4.670 \\
\hline & $d f$ & 2.199 & 2.199 & 2.199 & 2.199 & 2.199 & 2.199 & 2.199 \\
\hline & $\eta^{2}$ & 0.03 & 0.04 & 0.03 & 0.01 & 0.02 & 0.03 & 0.05 \\
\hline & $p$ & 0.042 & 0.016 & 0.045 & 0.395 & 0.196 & 0.062 & 0.010 \\
\hline
\end{tabular}

Multiple comparison between groups (Post hoc test): ${ }^{*} p<0.05$ between normal and obese, ${ }^{* *} p<0.05$ between overweight and obese

Smoking

\begin{tabular}{|c|c|c|c|c|c|c|c|c|}
\hline \multirow[t]{2}{*}{ Current smoker } & Mean & 40.7 & 51.6 & 56.1 & 54.5 & 58.7 & 18.5 & $22.2^{*}$ \\
\hline & SD & 21.8 & 20.0 & 20.5 & 21.1 & 16.8 & 14.6 & 12.0 \\
\hline \multirow[t]{2}{*}{ Past smoker, quit } & Mean & 35.9 & 47.8 & 51.8 & 51.6 & $55.0^{* *}$ & 18.9 & $26.3^{* *}$ \\
\hline & SD & 21.3 & 17.6 & 16.6 & 21.6 & 17.1 & 14.4 & 9.6 \\
\hline \multirow[t]{6}{*}{ Never smoked } & Mean & 46.4 & 55.1 & 60.8 & 58.4 & 63.6 & 14.4 & 18.9 \\
\hline & SD & 22.9 & 17.7 & 18.5 & 19.9 & 15.1 & 11.3 & 10.9 \\
\hline & $\mathrm{F}$ & 2.453 & 1.591 & 2.327 & 1.296 & 3.414 & 2.625 & 4.082 \\
\hline & df & 2.199 & 2.199 & 2.199 & 2.199 & 2.199 & 2.199 & 2.199 \\
\hline & $\eta^{2}$ & 0.02 & 0.02 & 0.02 & 0.01 & 0.03 & 0.03 & 0.04 \\
\hline & $p$ & 0.089 & 0.206 & 0.100 & 0.276 & 0.035 & 0.075 & 0.018 \\
\hline \multicolumn{9}{|c|}{ Multiple comparison between groups (post hoc test): ${ }^{*} p<0.05$ between never smoked and current smokers, ${ }^{* *} p<0.05$ between never smoked and past smokers } \\
\hline \multicolumn{9}{|l|}{$\begin{array}{l}\text { Alcohol } \\
\text { consumption }\end{array}$} \\
\hline \multirow[t]{2}{*}{ Drinking } & Mean & 43.1 & 55.4 & 57.4 & 55.7 & 60.7 & 17.3 & 20.8 \\
\hline & SD & 23.0 & 17.3 & 20.1 & 19.7 & 16.1 & 12.2 & 11.8 \\
\hline \multirow[t]{2}{*}{$\begin{array}{l}\text { Used to drink } \\
\text { but quit }\end{array}$} & Mean & 35.6 & 47.9 & 54.9 & 52.5 & 57.4 & 18.2 & 23.2 \\
\hline & SD & 23.4 & 21.9 & 22.0 & 23.0 & 19.1 & 16.8 & 12.8 \\
\hline \multirow[t]{6}{*}{ Never drank } & Mean & 45.2 & 53.3 & 59.5 & 57.5 & 62.1 & 15.3 & 20.2 \\
\hline & SD & 22.1 & 18.5 & 18.4 & 20.5 & 15.5 & 12.5 & 11.0 \\
\hline & $\mathrm{F}$ & 1.570 & 1.219 & 0.619 & 0.574 & 0.794 & 0.765 & 0.593 \\
\hline & $d f$ & 2.199 & 2.199 & 2.199 & 2.199 & 2.199 & 2,199 & 2.199 \\
\hline & $\eta^{2}$ & 0.02 & 0.01 & 0.01 & 0.01 & 0.01 & 0.01 & 0.01 \\
\hline & $p$ & 0.211 & 0.298 & 0.539 & 0.564 & 0.453 & 0.467 & 0.554 \\
\hline
\end{tabular}

In comparing 2 groups, independent-samples t-test was used, when comparing 3 groups, one-way ANOVA was applied. BDI: Beck Depression Inventory, BAI: Beck Anxiety Inventory, BMI: Body Mass Index, SD: Standard deviation, df: Degrees of freedom

for overweight. Though no significant difference was seen between groups for the health and environment subdimension scores, both environment and social relations scores increased with rising BMI scores, the lowest mean value being found in the obese group. BDI and BAI mean scores increased with growing weight. A significant difference was found between BAI mean values $(\mathrm{F}=4.670 ; \mathrm{p}=0.010)$.

Regarding smoking status, the highest mean values for all subdimensions of quality of life were found in the non-smoker group, the lowest mean values in the group of quitters. The environment score showed a significant 
difference between non-smokers and quitters $(\mathrm{F}=3.414$; $\mathrm{p}=0.035$ ), while all other quality of life subscale scores showed no significant differences between groups. The highest BDI and BAI scores were found in the quitters' group, the lowest mean scores in the non-smoker group. While the BDI scores did not show any difference between groups, BAI mean scores were significantly higher among quitters and current smokers than among non-smokers $(\mathrm{F}=4.082 ; \mathrm{p}=0.018)$.

Looking at alcohol consumption, the highest mean scores for all quality of life variables except physical health were found in the lifetime abstainer group, while the lowest mean scores belonged to the group that had quit alcohol. The highest mean score for the physical health variable being in the lifetime abstainer group, the lowest mean value was, like for the other quality of life dimensions, in the quitters' group. Both for BDI and BAI, the highest mean value was found in the quitters' group, while the lowest mean was in the lifetime abstainer group; no significant difference between groups was found.

Table 5 presents the analysis results of multiple regression models generated by evaluating the variables found correlated in univariate analyses with each of the subscale scores as dependent variables. Depression symptom severity (general health $[\beta=-0.502 ; \mathrm{p}<0.001]$, physical health $[\beta=-0.469 ; \mathrm{p}<0.001]$, psychological health $[\beta=-0.305 ; p<0.001]$, social relations $[\beta=-0.640$; $\mathrm{p}<0.001]$, environment $[\beta=-0.371 ; \mathrm{p}<0.001])$ and anxiety symptom severity (general $[\beta=-0.216 ; p=0.002]$, physical $[\beta=-0.350 ; \mathrm{p}<0.001]$, psychological $[\beta=-0.393$; $\mathrm{p}<0.001]$, social relations $[\beta=-0.139 ; \mathrm{p}=0.039]$, environment $[\beta=-0.406 ; p<0.001])$ were found to be independent variables determining the levels of all 5 quality of life subdimensions. In addition, education level was seen to be an independent factor affecting the level of physical quality of life $(\beta=0.185 ; p=0.001)$, while diabetes type affected the level of social quality of life ( $\beta=-0.106 ; p=0.027)$. According to Table 5 , the models constructed with the variables used in the research are seen to have significant predictive power for the level of quality of life (general health $\left[\mathrm{R}^{2}=0.60 ; \mathrm{F}=35.61\right]$, physical health $\left[\mathrm{R}^{2}=0.72 ; \mathrm{F}=60.93\right]$, psychological health $\left[\mathrm{R}^{2}=0.50 ; \mathrm{F}=23.72\right]$, social relations $\left[\mathrm{R}^{2}=0.60 ; \mathrm{F}=36.50\right]$, environment $\left.\left[\mathrm{R}^{2}=0.73 ; \mathrm{F}=27.4\right]\right)$.

\section{DISCUSSION}

Of the study participants, $21.29 \%$ were type 1 diabetic patients, and all of them used insulin alongside diet and exercise. The onset of type 2 diabetes usually occurs

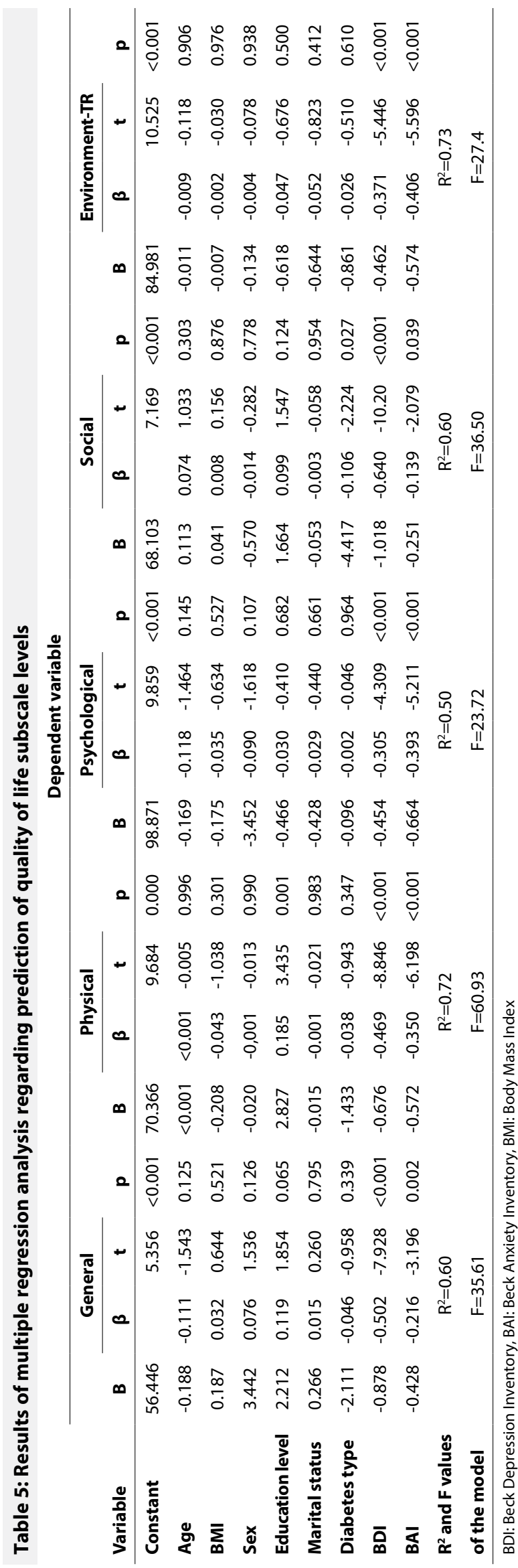


above the age of 40; the prevalence in the age group 20-60 years is $7.2 \%$; above age 60 it increases to $20 \%$. Ninety percent of diabetics are affected by type 2 diabetes (42). A study by Gokdogan and Akinci (43) found $21.4 \%$ of diabetes patients to be of type $1,78.6 \%$ were of type 2 . In our study, the fraction of type 2 diabetics was $58.9 \%$, a lower percentage than in the literature.

Our study found lower scores for quality of life subscores in type 1 diabetics (general health, physical health, psychological, environment, social relations) compared to type 2 patients. In multiple regression analysis, the type of diabetes was found to be a factor affecting the quality of life subdimension social life independently. Other studies similarly found the quality of life to be lower in type 1 diabetics (44). Possible reasons for the reduced quality of life in type 1 diabetes include the greater therapeutic effort, more frequent blood glucose control, exposure to the illness at an earlier age, and the greater incidence of chronic complications.

Popkin et al. (45) stated that most patients with type 1 diabetes have at least 1 psychiatric comorbidity. In a study evaluating anxiety, depression, and quality of life in type 1 and type 2 diabetics, Yuksel (46) found no depression in type 1 patients, light depression in type 2 patients, and light anxiety in both groups, but the quality of life of patients with light depression or anxiety was not affected. These results are different from those of our study. We found the depression symptom severity level in type 1 diabetic patients $(19.3 \pm 13.2)$ and the depression symptom severity level in type 2 diabetics $(14.0 \pm 12.3)$ to be significantly higher $(p=0.003)$. Evaluating their BDI scores, we found that type 1 diabetics participating in our research showed moderate depression symptoms requiring clinical assessment, while type 2 diabetics displayed low-level depression symptoms. In the same way, anxiety symptom severity levels in type 1 diabetes were significantly elevated $(\mathrm{p}=0.002)$. Type 1 diabetes begins at an earlier age than type 2 diabetes and treatment is more complicated than in type 2 diabetics, with more frequent follow-ups required. For these reasons, depression is more frequently seen in type 1 diabetics than in type 2 (25). Our results support this view.

Another study with adult type 1 and type 2 diabetics, enrolling 20 individuals in the study group and 22 controls, found a twice greater prevalence of depression and anxiety in the patients compared to the control group (47). In their study with diabetic patients, Gulseren et al. (32) reported having found major depressive disorder in $15 \%$ of participants, and the quality of life of patients with high scores from depression and anxiety scales was impaired and the amount of disability increased. In our study, we found a mean depression symptom severity for all diabetic patients of $\bar{x}=16.2 \pm 12.9$ (light to moderate depression). As we did not make a diagnostic assessment but rather looked at the symptom level, the percentage of major depression among the participants cannot be provided. But the observation that in our regression model quality of life declined with increasing anxiety and depression symptom severity is consistent with the results published by Gulseren et al. (32).

In diabetic patients, hypoglycemia and problems originating in functions of the respiratory, cardiovascular, and homeostatic systems may cause a significant level of anxiety $(48,49)$. Anxiety has been found closely related with reduced functionality and quality of life (33). A study with 2584 diabetic patients and a control group of 1492 participants found anxiety disorder in $14 \%$ of diabetics, and in $27 \%$ anxiety symptoms were on the increase; anxiety symptoms were significantly higher in women than in men (33). It has been reported that variables like being of the female sex, diabetes-related complications, an increasing number of hospitalizations due to diabetes, lack of information about the disease, low levels of education and income, and insulin use may increase the level of anxiety, but in these studies, the type of diabetes did not affect the anxiety level $(2,15,33)$. In contrast to those studies, our work determined a significant sex difference in anxiety and depression symptom severity, with a significantly higher anxiety symptom severity in type 1 diabetes compared to type 2 . However, similar to the mentioned studies, anxiety symptom severity was found to be related with low quality of life. Multiple regression analysis found depression and anxiety symptom severity to be an independent variable determining all 5 of the quality of life levels (general, physical, psychological, social, and environmental health).

Studies concerned with sex differences in quality of life among diabetic patients reported poorer quality of life in women compared to men (50). In a study with type 2 diabetic patients using the Medical Outcomes Study Short Form-36, Papadopoulos et al. (51) found a lower quality of life in women. Another study using the same instrument again found low quality of life in type 2 diabetic women (52). In our study, we found a lower quality of life in women according to the general health subdimension, though not for the physical, psychological, social, and environmental subdimensions. 
Our study found a significant positive correlation between age and depression and anxiety symptom severity in diabetic patients: With older age, depression and anxiety symptom severity increases, while at the same time quality of life subdimensions general health, physical health, social relations, and environment decline. In our literature review, long-term diseases cause impairment to a person's body and functionality, and due to the presence and nature of a long-term disease, patients begin to experience psychological difficulties. In a study with 4510 patients suffering from a chronic illness, Li et al. (53) found that with age, problems caused by diabetes increased and quality of life declined. Uncertainties in the course of the disease, difficulties complying with the treatment, side effects, and problems in the relation with other persons, including healthcare staff, increase with age in diabetic patients as they do in all individuals with chronic diseases. The increase of this kind of problems with age could explain why diabetics over time experience a decline in quality of life and a rise in depression and anxiety symptom severity.

Studies investigating the variable marital status observe a lower quality of life in unmarried individuals compared to married persons $(51,54)$. A review paper by Rubin and Peyrot (55) reported a correlation of marriage and quality of life in the general population, and unmarried persons showed more frequent symptoms of depression than married individuals. The same review reported that the quality of life of divorced persons was lower than that of unmarried or married people. In our study, being single showed a positive correlation with all subdimensions of quality of life in diabetic patients and a negative correlation with depression and anxiety symptom severity. In addition, quality of life of widowed diabetics declined compared to married participants and depression and anxiety symptom severity increased. Thus, being single improved the quality of life for diabetic patients and reduced depression and anxiety symptom severity.

In their study with 4510 participants suffering from long-term illness, Li et al. (53) reported a significant correlation of education level and smoking with quality of life; with lower education level, quality of life was reduced. In a study with $21.4 \%$ type 1 and $78.6 \%$ type 2 diabetics, Gokdogan and Akinci (43) reported that $18.6 \%$ of participants were illiterate, 51.4 were literate or had completed primary school, $21.4 \%$ had finished secondary education and $8.6 \%$ higher education; with a higher education level, patients' compliance with treatment improved. The study by Yuksel (46) also found improved compliance with higher education levels in diabetic patients. A study investigating the relation between diabetic patients' attitude towards the disease and problem areas found that patients needed special education; non-insulin-using patients tended not to take the disease seriously, and the more illnessrelated problems increased, the greater was the demand for special education; a correlation was found between the patients' physical care and control and attitudes towards the disease (56). Many problems supposedly being experienced due to the disease may actually be of psychological origin, depending upon how the patients perceive their disease and themselves (57). It has been found that with lower education level, type 2 diabetic patients' sensitivity towards the disease and their ability to take the disease seriously were significantly lower (58). In a study with type 2 diabetic patients by Akin (13), it was found that university graduates had the highest level of information and the lowest level of depression, and the quality of life was higher in persons who had less negative perception and a less despondent/ reproachful, submissive attitude. Studies have shown that diabetes education shortens the duration of hospitalization and reduces the number of foot amputations by $50 \%$ and cases of blindness and chronic renal failure by $30 \%$ (59). Our study found a significant positive correlation of quality of life in diabetic patients with education level regarding level of general health, physical health, psychological health, and social relations subdimensions. With higher education level, diabetic patients' quality of life improves. These findings are consistent with the literature. Multiple regression analysis also found education level to be an independent factor determining the level of physical health in quality of life. The importance of education level for the increase of quality of life is explained by the fact that diabetics have a particular responsibility for themselves during therapy and care; they need to realize the importance of therapy and have to be able to carry out the necessary measures according to the type of treatment regularly. The significant drop in depression and anxiety symptom severity scores with higher levels of education observed in the research supports these findings.

In the research, a significant negative correlation of the quality of life subdimensions general health, physical health, and psychological health with the variable weight has been determined. In studies with type 2 diabetics similar to our work, Akinci et al. (54) found a decline in quality of life in individuals with a BMI $>24 \mathrm{~kg} / \mathrm{m}^{2}$, while Gonen et al. (5) and Papadopoulos 
et al. (51) found reduced quality of life in obese persons. However, Wexler et al. (60) indicated that obesity, hypertension, and hypercholesterolemia were not correlated with quality of life in diabetes. Our study found a significant positive correlation between weight and anxiety symptom severity in diabetic patients, though no significant correlation was found between weight and depression symptom severity. By contrast, there are studies suggesting that obese persons are more often developing depression, and depressed persons have a greater risk of gaining weight (61). A number of studies showed that obesity and depression increase type 2 diabetes. The level of activity of obese persons is lower than that of normal individuals. Physical inactivity plays an important role in the development of type 2 diabetes, obesity, and depression. Physical inactivity leads to obesity, obesity to insulin resistance, and insulin resistance causes type 2 diabetes (62). The incidence of depression in persons with a low level of physical activity is higher than in active participants (63). While in our study obesity was significantly more prevalent among type 2 diabetics than among type 1 , depression and anxiety symptom severity was higher in type 1 than in type 2 . However, both in type 1 and in type 2 patients, depression and anxiety symptom severity scores were above the cutoff point, showing that in patients of both types depression and anxiety symptoms are present at a level that requires evaluation. Evaluating type 1 and type 2 patients together in this comparison by weight, the presence of different depression-related factors in type 1 diabetes (early onset, treatment problems, early complications), and lower obesity and weight gain compared to the amount observed in type 2 diabetes may have been confounding factors for the results by diabetes type. Therefore, future studies with larger sample groups separating diabetes types may be expected to produce different results.

Smoking in diabetes patients increases the risk of cardiovascular disease in particular (64-66). Tobacco use is known to reduce the quality of life in the general population. There are findings suggesting that diabetes advances in smokers (67). In a study with 70 elderly type 2 diabetic patients carried out by Arisoy (58), $32.9 \%$ stated that they were smoking. In our study, $30.3 \%$ of type 2 diabetics were smokers, a rate similar to that found by Arisoy (58). When assessing all participating diabetes patients, we find that alcohol use does not make any difference for quality of life and depression and anxiety symptom severity, but with smoking, the environment subdimension is higher in non-smokers than in quitters, while the anxiety symptom severity scores of non-smokers are lower than in past and in present smokers. In contrast to our study, Citil et al. (68) reported no correlation between smoking and quality of life in diabetic patients. However, that study included results of a comparison between a healthy control group and diabetic patients, while our study looked at differences in quality of life between smokers, quitters, and non-smokers within the diabetes group. Available research findings indicating that smoking in the whole population generally reduces quality of life may explain why no difference in quality of life between diabetics and the healthy group was detected.

In our study, depression and anxiety symptoms and levels of quality of life in diabetic patients were assessed with self-report scales. Diagnoses and current treatment were determined from medical reports and statements from the patients during registration at the wellness center. We did not assess the patients' long- and shortterm blood glucose regulation measurements, possible complications they may have developed, and the duration of the disease with their effects on quality of life and depression and anxiety symptoms; in addition, no psychiatric diagnostic interviews were held and psychiatric comorbidities were not excluded, which are limitations of our study.

Finally, our study found type 1 diabetics' quality of life to be lower than in type 2 diabetics and concluded that early onset of diabetes, earlier development of complications, and treatment difficulties affected type 1 diabetics more than type 2 patients. Furthermore, depression and anxiety symptom severity was significantly higher in type 1 diabetics than in type 2 , and with the difference in quality of life, this was evaluated as an expected and significant result. The significant negative correlation between depression and anxiety symptom severity and quality of life in diabetics further supports this finding and emphasizes the importance of depression and anxiety symptoms for interventions aimed at improving diabetic patients' quality of life. No difference in anxiety and depression symptom severity was seen between the sexes in diabetic patients, though in women the general health aspect of quality of life was lower than in men. We found that diabetic patients' quality of life declined with age, depression and anxiety symptom severity grew, all subdimensions of quality of life increased with higher education levels, and a higher level of education reduced anxiety and depression symptoms. In addition, a correlation between smoking and low quality of life in diabetic patients was established, obesity was correlated 
with a reduction in the quality of life subfields general health, physical health, and psychological health, and weight gain correlated with an increase in anxiety symptom severity.

In order to protect the psychological health and improve the quality of life during the treatment of patients with chronic diseases like diabetes, it is important to know the relevant variables. From this perspective, we recommend considering these factors when planning illness education and psychosocial support according to the patient's education level. Considering the negative effects of depression and anxiety symptoms on the quality of life in diabetic patients, we recommend screening for depression and anxiety symptoms using standard screening tests, particularly in interventions aimed at improving their quality of life, and to plan early and effective interventions in these areas when providing psychological support.

\begin{tabular}{|c|c|c|}
\hline \multicolumn{2}{|c|}{ Contribution Categories } & Author Initials \\
\hline \multirow{3}{*}{ Category 1} & Concept/Design & S.C., E.G. \\
\hline & Data acquisition & S.C., E.G. \\
\hline & Data analysis/Interpretation & S.C. \\
\hline \multirow{2}{*}{ Category 2} & Drafting manuscript & S.C., E.G. \\
\hline & Critical revision of manuscript & S.C. \\
\hline Category 3 & Final approval and accountability & S.C., E.G. \\
\hline \multirow{2}{*}{ Other } & Technical or material support & S.C., E.G. \\
\hline & Supervision & S.C. \\
\hline
\end{tabular}

Ethics Committee Approval: This study has been carried out in conformity with the internationally recognized Helsinki Declaration of 1964, latest revision 2013, and approval from the scientific research ethics committee of Cag University was given on March 25, 2019, document no. 999.

Informed Consent: Written informed consent of all patients was obtained.

Peer-review: Externally peer-reviewed.

Conflict of Interest: The author(s) declared no potential conflicts of interest with respect to the research, authorship, and/or publication of this article.

Financial Disclosure: The author(s) received no financial support for the research, authorship and/or publication of this article.

\section{REFERENCES}

1. TURKDIAB. Guide to the Diagnosis and Treatment of Diabetes. Seventh ed., Istanbul: Turkiye Diyabet Vakfi, 2017. (Turkish)

2. Bahar A, Sertbas G, Sonmez A. Determination of depression and anxiety levels of patients with diabetes mellitus. Anadolu Psikiyatri Derg 2006; 7:18-26.
3. Eren I, Erdi O, Civi I. The quality of life in the patients with type II diabetes mellitus and effects of complications on the quality of life. Klinik Psikiyatri 2004; 7:85-94. (Turkish)

4. Ozdemir I, Hocaoglu C, Kocak M, Ersoz OH. Quality of life and psychiatric symptoms in the patients with type 2 diabetes mellitus. Dusunen Adam The Journal of Psychiatry and Neurological Sciences 2011; 24:128-138.

5. Gonen S, Gungor K, Cilli AS, Kamis U, Akpinar Z, Kisakol G, et al. Comprehensive analysis of health related quality of life in patients with diabetes: A study from Konya-Turkey. Turk J Endocrinol Metab 2007; 11:81-88.

6. Demirci H, Cinar Y, Bayram N, Bilgel N. Quality of life in type II diabetic patients in primary health care. Dan Med J 2012; 59:A4468.

7. Debono M, Cachia E. The impact of diabetes on psychological well being and quality of life. The role of patient education. Psychol Health Med 2007; 12:545-555.

8. Huang MF, Courtney M, Edwards H, McDowell J. Factors that affect health outcomes in adults with type 2 diabetes: a crosssectional study. Int J Nurs Stud 2010; 47:542-549.

9. Holton DR, Colberg SR, Nunnold T, Parson HK, Vinik AI. The effect of an aerobic exercise training program on quality of life in type 2 diabetes. Diabetes Educ 2003; 29:837-846.

10. Toobert DJ, Glasgow RE, Strycker LA, Barrera M Jr, Radcliffe JL, Wander RC, et al. Biologic and quality-of-life outcomes from the Mediterranean Lifestyle Program: a randomized clinical trial. Diabetes Care 2003; 26:2288-2293.

11. Bennett WL, Ouyang P, Wu AW, Barone BB, Stewart KJ. Fatness and fitness: how do they influence health-related quality of life in type 2 diabetes mellitus? Health Qual Life Outcomes 2008; 6:110.

12. Kocaman N, Ozkan M, Armay Z, Ozkan S. The reliability and the validity study of Turkish adaptation of the revised Illness Perception Questionnaire. Anadolu Psikiyatri Derg 2007; 8:271280.

13. Akin AI. Quality of life, illness knowledge level, illness perception and style of coping with stress in people with type 2 diabetes. Postgraduate Thesis, Okan University, Department of Psychology, Istanbul, 2013. (Turkish)

14. Eren I, Erdi O. The effect of diabetic complications on psychiatric comorbidity in type II diabetic patients. Psikiyatri Psikoloji Psikofarmakoloji (3P) Dergisi 2004; 12:209-216. (Turkish)

15. Collins MM, Corcoran P, Perry IJ. Anxiety and depression symptoms in patients with diabetes. Diabet Med 2009;26:153161.

16. Egede LE, Nietert PJ, Zheng D. Depression and all-cause and coronary heart disease mortality among adults with and without diabetes. Diabetes Care 2005; 28:1339-1345.

17. Gois C, Akiskal H, Akiskal K, Figueira ML. Depressive temperament, distress, psychological adjustment and depressive symptoms in type 2 diabetes. J Affect Disord 2012; 143:1-4.

18. Kyrou I, Tsigos C. Stress hormones: physiological stress and regulation of metabolism. Curr Opin Pharmacol 2009; 9:787-793. 
19. Chrousos GP. Stress and disorders of the stress system. Nat Rev Endocrinol 2009; 5:374-381.

20. Herbert J, Goodyer IM, Grossman AB, Hastings MH, de Kloet ER, Lightman SL, et al. Do corticosteroids damage the brain? J Neuroendocrinol 2006; 18:393-411.

21. Moulton CD, Costafreda SG, Horton P, Ismail K, Fu CH. Metaanalyses of structural regional cerebral effects in type 1 and type 2 diabetes. Brain Imaging Behav 2015;9:651-662.

22. Pickup JC, Crook MA. Is type II diabetes mellitus a disease of the innate immune system? Diabetologia 1998; 41:1241-1248.

23. Wang X, Bao W, Liu J, Ouyang YY, Wang D, Rong S, et al. Inflammatory markers and risk of type 2 diabetes: a systematic review and meta-analysis. Diabetes Care 2013; 36:166-175.

24. Raison CL, Capuron L, Miller AH. Cytokines sing the blues: inflammation and the pathogenesis of depression. Trends Immunol 2006; 27:24-31.

25. Moulton CD, Pickup JC, Ismail K. The link between depression and diabetes: the search for shared mechanisms. Lancet Diabetes Endocrinol 2015; 3:461-471.

26. Korczak DJ, Pereira S, Koulajian K, Matejcek A, Giacca A. Type 1 diabetes mellitus and major depressive disorder: evidence for a biological link. Diabetologia 2011; 54:2483-2493.

27. Dipnall JF, Pasco JA, Meyer D, Berk M, Williams LJ, Dodd S, et al. The association between dietary patterns, diabetes and depression. J Affect Disord 2015; 174:215-224.

28. Dirmaier J, Watzke B, Koch U, Schulz H, Lehnert H, Pieper L, et al. Diabetes in primary care: prospective associations between depression, nonadherence and glycemic control. Psychother Psychosom 2010; 79:172-178.

29. Zuberi SI, Syed EU, Bhatti JA. Association of depression with treatment outcomes in Type 2 Diabetes Mellitus: a cross-sectional study from Karachi, Pakistan. BMC Psychiatry 2011; 11:27.

30. Ecemis GC, Kaya A. Type 1 diabetic in a long honeymoon period: case presentation. 35th Turkish Endocrinology and Metabolism Diseases Congress \& Hypophysis Symposium, Antalya, Proceedings Book, 2013, 282. (Turkish)

31. Kebapcilar, L. Case session. 35. Turkish Endocrinology and Metabolism Diseases Congress \& Hypophysis Symposium, Antalya, Proceedings Book, 2013, 185-186. (Turkish)

32. Gulseren L, Hekimsoy Z, Gulseren S, Bodur Z, Kultur S. Depression-Anxiety, Quality of Life and Disability in Patients with Diabetes Mellitus. Turk Psikiyatri Derg 2001; 12:89-98.

33. Grigsby AB, Anderson RJ, Freedland KE, Clouse RE, Lustman PJ. Prevalence of anxiety in adults with diabetes: a systematic review. J Psychosom Res 2002; 53:1053-1060.

34. Zhang CX, Chen YM, Chen WQ. Association of psychosocial factors with anxiety and depressive symptoms in Chinese patients with type 2 diabetes. Diabetes Res Clin Pract 2008; 79:523-530.

35. Konca G. Investigation of the Depression and Anxiety Rates in Type 1 Diabetic Patients. Postgraduate Thesis, Beykent University, Health Sciences Institute, Istanbul, 2015. (Turkish)
36. Development of the World Health Organization WHOQOLBREF quality of life assessment. The WHOQOL Group. Psychol Med 1998; 28:551-558.

37. Eser E, Fidaner H, Fidaner C, Eser SY, Elbi H, Goker E. Psychometric properties of the WHOQOL-100 and WHOQOLBREF. Psikiyatri Psikoloji Psikofarmakoloji (3P) Dergisi 1999; 7(Suppl.2):23-40.

38. Beck AT, Ward CH, Mendelson M, Mock J, Erbaugh J. An inventory for measuring depression. Arch Gen Psychiatry 1961; 4:561-571.

39. Hisli N. Validity and reliability of the Beck Depression Inventory in university students. Psikoloji Dergisi 1989; 7:3-13. (Turkish)

40. Ulusoy M, Sahin N, Erkmen H. Turkish version of the Beck Anxiety Inventory: Psychometric properties. J Cogn Psychother 1998 ; $12: 163-182$.

41. Guleç H, Sayar K, Ozkorumak E. Somatic symptoms of depression. Turk Psikiyatri Derg 2005; 16:90-96. (Turkish)

42. Altun BU. The follow-up of diabetic patient in polyclinic. Trakya Universitesi Tip Fakultesi Dergisi 2010; 27(Suppl.1):1925. (Turkish)

43. Gokdogan F, Akinci F. Practices and perceptions about their health and diseases of patients with diabetes mellitus in Bolu. Cumhuriyet Universitesi Hemsirelik Yuksekokulu Dergisi 2001; 5:10-17. (Turkish)

44. Nielsen HB, Ovesen LL, Mortensen LH, Lau CJ, Joensen LE. Type 1 diabetes, quality of life, occupational status and education level - A comparative population-based study. Diabetes Res Clin Pract 2016; 121:62-68.

45. Popkin MK, Callies AL, Lentz RD, Colon EA, Sutherland DE. Prevalence of major depression, simple phobia, and other psychiatric disorders in patients with long-standing type I diabetes mellitus. Arch Gen Psychiatry 1988; 45:64-68.

46. Yuksel S. Evaluation of Sleep Quality, Anxiety, Depression and Life Quality of Type 1 and Type 2 Diabetic Patients. Postgraduate Thesis, Afyon Kocatepe University, Health Sciences Institut. Afyon, 2007. (Turkish)

47. Anderson RJ, Freedland KE, Clouse RE, Lustman PJ. The prevalence of comorbid depression in adults with diabetes: a meta-analysis. Diabetes Care 2001; 24:1069-1078.

48. Adakan FY, Vural R, Sahintürk Y, Boylubay SM, Yllmaz U, Kulaksızoğlu B, et al. The relation of socio-demographic and clinical factors to depression and anxiety levels in diabetic patients. Konuralp Tip Dergisi 2017; 9:96-105.

49. Kucuk L. Psychological aspects of diabetes. Okmeydani Tip Dergisi 2015; 31(Suppl):52-56. (Turkish)

50. Glasgow RE, Ruggiero L, Eakin EG, Dryfoos J, Chobanian L. Quality of life and associated characteristics in a large national sample of adults with diabetes. Diabetes Care 1997; 20:562567.

51. Papadopoulos AA, Kontodimopoulos N, Frydas A, Ikonomakis E, Niakas D. Predictors of health-related quality of life in type II diabetic patients in Greece. BMC Public Health 2007; 7:186. 
52. Bilgin MS, Ozenc S, Sari O, Yesilkaya S, Aydogan U, Koc B. A study on quality of life patients with diabetes. J Clin Anal Med 2015; 6:159-163.

53. Li W, Liu L, Puente JG, Li Y, Jiang X, Jin S, et al. Hypertension and health-related quality of life: an epidemiological study in patients attending hospital clinics in China. J Hypertens 2005; 23:16671676.

54. Akinci F, Yildirim A, Gözü H, Sargin H, Orbay E, Sargin M. Assessment of health-related quality of life (HRQoL) of patients with type 2 diabetes in Turkey. Diabetes Res Clin Pract 2008; 79:117-123.

55. Rubin RR, Peyrot M. Quality of life and diabetes. Diabetes Metab Res Rev 1999; 15:205-218.

56. Sahin ZA. The attitude of patiens [sic] with diabetes type 2 and the correlation between the problem fields. ODU Tip Dergisi 2015; 2:134-138. (Turkish)

57. Dirik G, Yorulmaz E. Psychosocial processes and psychological interventions in diabetes patients: In Krespi MR (editor). Psychosocial Processes in Chronic Physical Diseases. Ankara: Türkiye Klinikleri, 2018, 1-12. (Turkish)

58. Arisoy H. Attitudes of elderly patients with diabetes towards illness and health. Master Thesis, Hacettepe University Institute of Health Sciences, Ankara, 2013. (Turkish)

59. Isik NA, Buzlu S. Compared [sic] to depressive symptoms of type 2 diabetic patients who were treated with oral anti-diabetic drugs and insulin. Gazi Medical Journal 2016; 27:189-192. (Turkish)

60. Wexler DJ, Grant RW, Wittenberg E, Bosch JL, Cagliero E, Delahanty L, et al. Correlates of health-related quality of life in type 2 diabetes. Diabetologia 2006; 49:1489-1497.
61. Rajan TM, Menon V. Psychiatric disorders and obesity: A review of association studies. J Postgrad Med 2017; 63:182-190.

62. Gratas-Delamarche A, Derbré F, Vincent S, Cillard J. Physical inactivity, insulin resistance, and the oxidative-inflammatory loop. Free Radic Res 2014; 48:93-108.

63. Gallegos-Carrillo K, Flores YN, Denova-Gutiérrez E, MéndezHernández P, Dosamantes-Carrasco LD, Henao-Morán S, et al. Physical activity and reduced risk of depression: results of a longitudinal study of Mexican adults. Health Psychol 2013; 32:609-615.

64. Foulis AK, Stewart JA. The pancreas in recent-onset type 1 (insulin-dependent) diabetes mellitus: insulin content of islets, insulitis and associated changes in the exocrine acinar tissue. Diabetologia 1984; 26:456-461.

65. Sikoglu OK. An investigation of some morphometric parameters measured by echocardiography in coronary slow flow phenomenon. Unpublished Postgraduate Thesis, Firat University, Health Sciences Institute. Elazig, 2015. (Turkish)

66. Yildirim D. Assessment of Care Needs for Adult Type 1 Diabetics: Preliminary Study for the Development of a Model of Care. Unpublished Postgraduate Thesis, Istanbul University, Health Sciences Institute. Istanbul, 2013. (Turkish)

67. Nelson RG, Knowler WC, Pettitt DJ, Bennett PH. National Diabetes Data Group. Kidney diseases in diabetes: In Harris MI, Cowie CC, Stern MP, Boyko EJ, Reiber GE, Bennett PH (editors). Diabetes in America. Second Ed. Bethesda, Md: National Institutes of Health, National Institute of Diabetes and Digestive and Kidney Diseases, 1995, 349-400.

68. Citil R, Gunay O, Elmali F, Ozturk Y. The effects of medical and social factors on the quality of life of diabetic patients. Erciyes Tip Dergisi 2010; 32:253-264. (Turkish) 